\title{
The effect of radiological contrast media on renal function and inflammatory markers in people with diabetes - a clinical study and review
}

\author{
MARK BAXTER, ${ }^{1}$ CATHERINE GOODAY, ${ }^{2}$ KETAN DHATARIYA ${ }^{1,2}$
}

\begin{abstract}
Aim: To assess the association of inflammatory markers and the risk of developing contrast-induced nephropathy (CIN) in patients with diabetes undergoing lower limb angiography.

Methods: This was a retrospective study of 77 patients undergoing lower limb angiography. We measured renal function and markers of inflammation, in particular neutrophil and lymphocyte count and C-reactive protein (CRP) levels, before and at 24, 48 and $\mathbf{7 2}$ hours after administration of contrast medium.

Results: Those with pre-existing renal disease were at increased risk of CIN. We found no relationship between baseline renal function and CRP. There was a reduction in haemoglobin and lymphocyte count that is currently unexplained.

Conclusions: While several traditional risk factors for CIN have been identified, further work is needed to determine the significance of changes in other haematological parameters.

Br J Diabetes Vasc Dis 2015;15:187-191
\end{abstract}

Key words: diabetes, angiography, contrast, contrast-induced nephropathy, inflammatory markers

\section{Introduction}

Contrast-induced nephropathy $(\mathrm{CIN})$ is a form of acute kidney injury that occurs secondary to the administration of contrast medium (CM) and is not attributable to any other cause. ${ }^{1}$ CIN has been reported as the third most common cause of acute

Department of Medicine, Norfolk and Norwich University Hospitals NHS Foundation Trust, Norwich, UK

2 Diabetic Foot Clinic, Elsie Bertram Diabetes Centre, Norfolk and Norwich University Hospitals NHS Foundation Trust, Norwich, UK

Address for correspondence: Dr Ketan Dhatariya

Consultant in Diabetes and Endocrinology, Diabetic Foot Clinic, Elsie Bertram Diabetes Centre, Norfolk and Norwich University Hospitals NHS

Foundation Trust, Colney Lane, Norwich, Norfolk, NR4 7UY, UK

Tel: +44 (0)1603 288170

E-mail: ketan.dhatariya@nnuh.nhs.uk

http://dx.doi.org/10.15277/bjdvd.2015.040 kidney injury occurring in hospital, after surgery and hypotension. ${ }^{2}$

Until recently, CIN had been defined as a rise in serum creatinine of $\geq 50 \mu \mathrm{mol} / \mathrm{L}$, or a $25 \%$ increase from baseline, assessed within 48-72 hours after administration of CM. ${ }^{3}$ In 2013 a new definition was accepted, based on the following findings after administration of CM: a rise of serum creatinine of $>1.5$ times the baseline value within seven days, an absolute increase of more than $26 \mu \mathrm{mol} / \mathrm{L}$ within two days, or urine output $<0.5$ $\mathrm{mL} / \mathrm{kg} / \mathrm{hr}$ for more than six hours following the procedure. ${ }^{4}$ Rising numbers of radiological procedures using CM have led to CIN becoming a significant source of morbidity and mortality, and it has been estimated that CIN accounts for $10 \%$ of all cases of iatrogenic acute kidney disease. ${ }^{5}$

$\mathrm{CIN}$ is usually transient and reversible. Its pathogenesis is poorly understood, but is thought to be mediated in part by changes in renal haemodynamics and alterations in the balance of renal vascular vasodilators and vasoconstrictors, leading to reduced blood flow. ${ }^{6}$ Diabetes is one of a number of independent risk factors for developing CIN (along with hypotension, use of an intra-aortic balloon pump, heart failure, advanced age, high serum creatinine, anaemia, chronic kidney disease (CKD) and administration of a large volume of $(\mathrm{CM}),{ }^{7}$ and evidence is emerging for a role of the inflammatory marker C-reactive protein (CRP). ${ }^{8-11}$ CRP has been implicated in preventing vasodilation by increasing the activity of inhibitors of nitric oxide synthase and is widely recognised as a non-specific marker for systemic inflammation.12 Insulin resistance and diabetes are recognised as a generalised inflammatory states with raised CRP concentrations. ${ }^{13}$

The aim of our study was to assess the effect of CM on renal function and inflammatory markers in patients with diabetes with and without pre-existing renal impairment. We also looked at the effect of pre-existing inflammation, as measured by CRP, on the risk of developing CIN.

\section{Methods}

Patients and study design

This was a single centre retrospective cohort study, which was conducted as a service improvement exercise so ethical approval was not required. We identified all patients at our institution who underwent a lower limb angiogram after receiving CM (iohexol, a 
Table 1 Change in renal function (estimated glomerular filtration rate [eGFR]) after administration of contrast medium, shown for the cohort as a whole and for patients stratified for categories of severity of chronic kidney disease (CKD) at baseline

\begin{tabular}{|c|c|c|c|c|c|}
\hline & Overall & CKD1 $(n=15)$ & CKD2 $(n=23)$ & CKD3 $(n=29)$ & CKD4 $(n=7$ \\
\hline $\begin{array}{l}\text { Mean change }( \pm S D) \text { in eGFR } \\
\text { from baseline to } 72 \text { hours } \\
\left(\mathrm{mL} / \mathrm{min} / 1.73 \mathrm{~m}^{2}\right)\end{array}$ & $-5.1 \pm 27.5$ & $-8.5 \pm 6.8$ & $-3.7 \pm 19.8$ & $-5.4 \pm 11.2$ & $-1.3 \pm 4.9$ \\
\hline Mean \% change $( \pm S D)$ from baseline & $-8.4 \pm 10.1$ & $-8.2 \pm 18.2$ & $-5.2 \pm 4.8$ & $-12.0 \pm 9.4$ & $-5.2 \pm 4.9$ \\
\hline p (baseline vs. 72hours) & $<0.01$ & 0.227 & 0.088 & 0.104 & 0.647 \\
\hline n (at 72 hours) & 31 & 9 & 8 & 10 & 4 \\
\hline
\end{tabular}

Data are mean \pm SD, where applicable. CKD1: eGFR >90 mL/min/1.73m²; CKD2: eGFR 60-90 mL/min/1.73m²; CKD3: eGFR of 30-60 mL/min/1.73m²; CKD4: eGFR $<30 \mathrm{~mL} / \mathrm{min} / 1.73 \mathrm{~m}^{2}$

non-ionic monomer containing $140-350 \mathrm{mg} / \mathrm{mL}$ of iodine) between 1st January 2009 and 31st December 2010, using a database relating to our specialist diabetes vascular foot clinic. Procedures were conducted as an outpatient or inpatient, to assess peripheral vascular circulation for non-healing foot ulcers. The volume of CM given was determined according to the degree of arterial pathology within the usual care procedures of the radiologist undertaking the procedure.

We compared patients' baseline renal function (creatinine and estimated glomerular filtration rate [eGFR]) with available values 24, 48 and 72 hours after administration of CM. We also measured haemoglobin, white cell count and its white cell differential, and CRP. Patients without a blood test recorded within 1 week prior to the procedure or 72 hours after the procedure were excluded. Baseline eGFR levels were used to classify patients into relevant CKD sub-groups. Patients were also divided into two groups: "noninflammatory" or "inflammatory" based on their CRP at baseline; a cut-off value for CRP of $16 \mathrm{mg} / \mathrm{L}$ was chosen for this purpose as higher values have been reported to be an independent risk factor for $\mathrm{CIN} .{ }^{11}$ As this was a retrospective study, data were not available for all time points for all patients.

The Royal College of Radiologists recommends that metformin need not be withdrawn for people with normal renal function who undergo angiography. ${ }^{14}$ We withdrew metformin 48 hours before administration of CM for all patients, according to our hospital protocol.

\section{Statistical analyses}

Data are expressed as means \pm SD. Statistical significance was assessed using paired t-tests. The relationships between some continuous variables were explored using Pearson correlation coefficients.

\section{Results}

Of 84 patients who were eligible for our study, seven did not have data available and were therefore excluded. Our analyses are based on the remaining 77 patients, of whom 52 had data at 24 hours, 23 had data at 48 hours and 31 had data at 72 hours; only seven patients had data available for all time points. Of the 77 eligible patients, 54 were male and 23 were female.
All had diabetes. Their mean age was $73.8 \pm 9.4$ years. No patients with end-stage renal failure (eGFR $\left.<15 \mathrm{~mL} / \mathrm{min} / 1.73 \mathrm{~m}^{2}\right)$ underwent an angiographic procedure.

Renal function (eGFR) across the entire cohort was significantly $(p<0.01)$ lower 72 hours after receiving CM (Table 1$)$, and was also reduced between 24 hours and 48 hours after administration of $C M(p=0.0377$, data not shown). Marked changes in serum creatinine were uncommon: 25/77 patients had baseline creatinine $>120 \mu \mathrm{mol} / \mathrm{L}$ and, of these, one patient went from serum creatinine concentration of $221 \mu \mathrm{mol} / \mathrm{L}$ (baseline) to 240 $\mu \mathrm{mol} / \mathrm{L}$ (72 hours), and another went from $163 \mu \mathrm{mol} / \mathrm{L}$ (baseline), to $164 \mu \mathrm{mol} / \mathrm{L}$ (24 hours), $237 \mu \mathrm{mol} / \mathrm{L}$ (48 hours) and $273 \mu \mathrm{mol} / \mathrm{L}$ (72 hours). There were no marked changes in serum creatinine in the remaining patients.

The overall incidence of CIN (defined as 25\% rise in creatinine within 72 hours) was 5/77 (6.5\%). All had pre-existing renal impairment (one with stage 2 CKD [CKD2], three with stage 3 CKD [CKD3] and one with stage 4 CKD [CKD4]).

Haemoglobin was significantly lower at both 48 hours and at 72 hours (Table 2). When assessed according to baseline renal function, only those classified as CKD3 demonstrated a significant difference at 48 and 72 hours $(p=0.042$ and $p=0.03$ respectively, data not shown). There was no significant difference in baseline haemoglobin according to renal function at baseline. About half of our patients $(44 / 77 ; 54.5 \%)$ were classified as anaemic prior to the administration of $\mathrm{CM}$, but this was not associated with an increased risk of CIN (data not shown).

Table 2 also shows data for inflammatory markers. There were no significant changes over time in white cell count, CRP or neutrophil count, although the lymphocyte count was reduced significantly at 48 hours $(p=0.003)$ and at 72 hours $(p=0.008)$. Changes in the neutrophil:leucocyte ratio at $48-72$ hours did not correlate with changes in creatinine at these times (correlation coefficient 0.0071 ), suggesting that there was no relationship between changes in this ratio and changes in renal function.

Ten patients had "non-inflammatory" levels of CRP and 14 patients had "inflammatory" levels of CRP (mean baseline CRP levels were $3.8 \pm 4.4$ and $95.1 \pm 52.3 \mathrm{mg} / \mathrm{L}$, respectively, $p<0.0001)$. Changes in eGFR in the non-inflammatory and 
Table 2 Changes in haemoglobin and parameters related to inflammation

\begin{tabular}{|c|c|c|c|c|}
\hline & \multirow[b]{2}{*}{ Baseline $(n=73)$} & \multicolumn{3}{|c|}{ Mean changes following administration of contrast medium } \\
\hline & & +24 hours $(n=44)$ & +48 hours $(n=20)$ & +72 hours $(n=29)$ \\
\hline Haemoglobin $(\mathrm{g} / \mathrm{dL})$ & $\begin{array}{l}n=73 \\
12.3 \pm 2.07\end{array}$ & $\begin{array}{l}n=44 \\
-0.2 \pm 1.2 \\
p=0.319\end{array}$ & $\begin{array}{l}n=20 \\
-0.7 \pm 1.1 \\
p=0.0074\end{array}$ & $\begin{array}{l}n=29 \\
-0.8 \pm 1.2 \\
p=0.0015\end{array}$ \\
\hline White cell count $\left(\times 10^{9} / L\right)$ & $\begin{array}{l}n=73 \\
9.4 \pm 3.16\end{array}$ & $\begin{array}{l}n=44 \\
0.1 \pm 1.6 \\
p=0.734\end{array}$ & $\begin{array}{l}n=20 \\
-0.7 \pm 2.1 \\
p=0.160\end{array}$ & $\begin{array}{l}n=29 \\
0.7 \pm 3.1 \\
p=0.243\end{array}$ \\
\hline C-reactive protein (mg/L) & $\begin{array}{l}n=41 \\
53.4 \pm 59.9\end{array}$ & $\begin{array}{l}n=33 \\
-2.6 \pm 27.4 \\
p=0.67\end{array}$ & $\begin{array}{l}n=19 \\
-3.2 \pm 57.1 \\
p=0.836\end{array}$ & $\begin{array}{l}n=27 \\
-2.8 \pm 57.6 \\
p=0.817\end{array}$ \\
\hline Neutrophils $\left(x 10^{9} / L\right)$ & $\begin{array}{l}n=73 \\
6.5 \pm 2.81\end{array}$ & $\begin{array}{l}n=44 \\
0.2 \pm 1.5 \\
p=0.42\end{array}$ & $\begin{array}{l}n=20 \\
-0.2 \pm 2.0 \\
p=0.614\end{array}$ & $\begin{array}{l}n=29 \\
1.0 \pm 3.0 \\
p=0.091\end{array}$ \\
\hline Lymphocytes (x109/L) & $\begin{array}{l}n=73 \\
1.8 \pm 0.82\end{array}$ & $\begin{array}{l}n=44 \\
-0.2 \pm 0.48 \\
p=0.071\end{array}$ & $\begin{array}{l}n=20 \\
-0.5 \pm 0.63 \\
p=0.003\end{array}$ & $\begin{array}{l}n=29 \\
-0.4 \pm 0.67 \\
p=0.008\end{array}$ \\
\hline
\end{tabular}

inflammatory groups were similar 72 hours following administration of CM $\left(6.9 \pm 7.0\right.$ vs. $-5.21 \pm 13.8 \mathrm{~mL} / \mathrm{min} / 1.73 \mathrm{~m}^{2}$, $\mathrm{p}=0.658$ ).

Renal function declined (any decrease in eGFR or increase in creatinine) in 20 patients between 48-72 hours following administration of CM and did not decline in a further 14 patients. There was no difference in CRP between these groups (47.7 \pm 48.3 vs. $65.9 \pm 74.7 \mathrm{mg} / \mathrm{L}, \mathrm{p}=0.559)$. Changes in CRP did not correlate with changes in eGFR at 72 hours (correlation coefficient 0.035 ), suggesting no relationship between these variables.

\section{Discussion}

\section{Pathophysiology of CIN}

It is believed that CIN arises due to a combination of factors and three main concepts have been described: medullary hypoxia secondary to increased plasma viscosity resulting in renal tubular necrosis; direct tubular cytotoxicity of CM; stimulation by CM of adenosine release with a predominant vasoconstrictor effect on the renal vasculature. ${ }^{15-17}$ Elevated CRP prior to exposure to CM is a significant and independent predictor of CIN; inflammation is a pro-thrombotic state and elevated levels of inflammatory markers may contribute to increased plasma viscosity and subsequent tubular damage. ${ }^{10,11}$

\section{Consequences of administration of contrast medium}

Our study supports previous findings that people with co-existing diabetes and renal dysfunction are at increased risk of $\mathrm{CIN}^{7,18,19}$ : all five of our patients who developed CIN had pre-existing CKD. The risk of CIN has been shown to be related to the severity of pre-existing $C K D, 20,21$ but the exact relationship and the point at which damage is most likely to occur has yet to be determined. Our study did not address this issue due to its relatively small sample size and missing data for some patients. The incidence of CIN of $6.5 \%$ in our cohort is consistent with previous reports in people with diabetes (5-29\%). ${ }^{22,23}$

\section{Inflammatory markers}

Elevated levels of inflammatory markers, in particular CRP, prior to administration of CM may play a role in CIN following coronary angiography. ${ }^{10,11}$ A recent study involving 423 patients found that $13.5 \%$ of patients with CRP $>5 \mathrm{mg} / \mathrm{dL}$ developed CIN, compared with $6.25 \%$ of patients with a lower level of CRP. ${ }^{24}$ We found no significant difference in renal function when patients were divided into groups depending on their CRP level at baseline. In addition, there did not appear to be an association between CRP and the severity of renal impairment following administration of CM. This is also likely to be due to our relatively small sample size.

It has also recently been reported that the neutrophil: lymphocyte ratio may be an independent risk factor for CIN, ${ }^{25}$ although we found no such correlation. Overall, we did not find a significant difference in the white cell count, neutrophil count or CRP. Our data relating to CRP may be skewed because the average baseline CRP was significantly elevated at $53.4 \mathrm{mg} / \mathrm{L}$, suggesting that a pro-inflammatory state already existed in a proportion of our patients, probably due to the presence of a foot ulcer. Although CRP levels tended to decline after administration of CM, the difference did not achieve statistical significance, once again probably due to the small sample size of our study. We did, however, observe a significant decrease in lymphocyte count at 48 and 72 hours after administration of CM. The reason for this is unclear, particularly as the other markers of infection and inflammation remained unchanged. It is possible that the CM may have an effect on lymphocyte production or stimulation, in line with previous data that suggested a role for T-lymphocytes in delayed hypersensitivity to CM. ${ }^{26-29}$ 


\section{Key messages}

- Contrast-induced nephropathy (CIN) is a commonly encountered phenomenon in patients with diabetes

- The risk is increased in those with pre-existing renal impairment undergoing angiography

- There are several factors that determine the development of CIN

- Little work has been done to assess the impact of contrast on markers of inflammation

\section{Haemoglobin}

In our study, we found that haemoglobin was significantly reduced at both 48 and 72 hours. This was probably due to haemodilution secondary to routine intravenous and oral rehydration following the procedure, ${ }^{30}$ although our study design did not permit follow-up beyond 72 hours. Previous work has shown that low haemoglobin before treatment is a risk factor for the development of CIN. ${ }^{31}$ Prior anaemia was not associated with an increased risk of CIN in our population and we did not observe a reduction in haemoglobin when patients were stratified according to eGFR at baseline.

\section{Limitations}

Our study has several limitations in addition to its small size, as described above. We did not record the prior use of angiotensin converting enzyme inhibitors or whether intravenous fluids were given prior to the administration of CM. Fluid administration may have been limited to those with pre-existing renal disease in an attempt to prevent any further deterioration. In addition, we did not collect the presence of contemporaneous infection in individual patients. It has previously been shown that the volume of CM administered is related to the risk of developing $\mathrm{CIN},{ }^{32}$ however, these data were not collected. Finally, given the retrospective nature of the study, we were unable to collect all of the data and were limited to those collected in 'real life' clinical practice.

\section{Conclusions}

In daily practice, CIN is an important clinical issue to consider when ordering any radiographic imaging involving the administration of CM. Patients with diabetes and, in particular, those with pre-existing renal disease are at particular risk of CIN. Further research is needed to define the role of inflammatory markers in the pathophysiology of CIN.

Conflict of interest The authors declare that they have no conflicts of interest

Funding All of the authors are employees of the UK National Health Service.

\section{References}

1. Barrett BJ, Parfrey PS. Prevention of nephrotoxicity induced by radiocontrast agents. N Engl J Med 1994;331:1449-50.
http://dx.doi.org/10.1056/NEJM199411243312111

2. Tublin ME, Murphy ME, Tessler FN. Current concepts in contrast mediainduced nephropathy. Am J Roentgenol 1998;171:933-9. http://dx.doi.org/10.2214/ajr.171.4.9762972

3. Mehran R, Nikolsky E. Contrast-induced nephropathy: Definition, epidemiology, and patients at risk. Kidney Int 2006;69:511-15. http://dx.doi.org/10.1038/sj.ki.5000368

4. Renal Association, Royal College of Radiologists, and British Cardiovascular Intervention Society. Prevention of contrast induced acute kidney injury (Cl-AKI) in adult patients. 2013. Available at https://www.rcr.ac.uk/ sites/default/files/publication/2013_RA_BCIS_RCR.pdf (last accessed June 29 2015).

5. Gallagher S, Knight C. Contrast-induced nephropathy in primary percutaneous coronary intervention. Heart 2011;97:1723-5. http://dx.doi.org/10.1136/heartjnl-2011-300517

6. Russo D, Minutolo R, Cianciaruso B, et al. Early effects of contrast media on renal hemodynamics and tubular function in chronic renal failure. J Am Soc Nephrol 1995;6:1451-8.

7. Mehran R, Ayming ED, Nikolsky E, et al. A simple risk score for prediction of contrast-induced nephropathy after percutaneous coronary intervention. J Am Coll Cardiol 2004:44:1393-9.

http://dx.doi.org/10.1016/ j.jacc.2004.06.068

8. Gleeson TG, Bulugahapitiya S. Contrast-induced nephropathy. Am J Roentgenol 2004;83:673-89. http://dx.doi.org/10.2214/ajr.183.6.01831673

9. McCullough PA, Wolyn R, Rocher LL, et al. Acute renal failure after coronary intervention: Incidence, risk factors, and relationship to mortality. Am J Med 1997;103:368-75. http://dx.doi.org/10.1016/S0002-9343(97)00150-2

10. Evola S, Lunetta M, Macaione F, et al. Risk factors for contrast induced nephropathy: A study among Italian patients. Indian Heart J 2014; 64:484-91. http://dx.doi.org/10.1016/j.ihj.2012.07.007

11. Liu Y, Tan N, Zhou Y-L, et al. High-sensitivity C-reactive protein predicts contrast-induced nephropathy after primary percutaneous coronary intervention. J Nephrol 2012;25:332-40. http://dx.doi.org/10.5301/jn.5000007

12. Schwedler SB, Kuhlencordt PJ, Ponnuswamy PP, et al. Native C-reactive protein induces endothelial dysfunction in ApoE -/- mice: Implications for iNOS and reactive oxygen species. Atherosclerosis 2007;195:e76-84. http://dx.doi.org/10.1016/j.atherosclerosis.2007.06.013

13. Haffner SM. Insulin resistance, inflammation, and the prediabetic state. Am J Cardiol 2003;92:18-26J.

http://dx.doi.org/10.1016/S0002-9149(03)00612-X

14. Royal College of Radiologists. Metformin: Updated guidance for use in diabetics with renal impairment. http://www.rcn.org.uk/_data/assets/ pdf_file/0011/258743/BFCR097_Metformin.pdf. 2009 (last accessed June 29 2015)

15. Persson PB, Tepel M. Contrast medium-induced nephropathy: The pathophysiology. Kidney Int 2014;69:S8-10. http://dx.doi.org/10.1038/sj.ki.5000367

16. Persson PB, Hansell P, Liss P. Pathophysiology of contrast medium-induced nephropathy. Kidney Int 2005;68:14-22. http://dx.doi.org/10.1111/j.1523-1755.2005.00377.x

17. Deray G, Martinez F, Cacoub P, et al. A role for adenosine calcium and ischemia in radiocontrast-induced intrarenal vasoconstriction. $\mathrm{Am} J$ Nephrol 1990;10:316-22. http://dx.doi.org/10.1159/000168126

18. Hall KA, Wong RW, Hunter GC, et al. Contrast-induced nephrotoxicity: The effects of vasodilator therapy. J Surg Res 1992;53:317-20. http://dx.doi.org/10.1016/0022-4804(92)90054-4

19. Parfrey PS, Griffiths SM, Barrett BJ, et al. Contrast material-induced renal failure in patients with diabetes mellitus, renal insufficiency, or both. $N$ Engl J Med 1989;320:143-9. http://dx.doi.org/10.1056/NEJM198901193200303

20. Lautin EM, Freeman NJ, Schoenfeld AH, et al. Radiocontrast-associated renal dysfunction: incidence and risk factors. Am J Roentgenol 2014; 57:49-58.

21. Rihal CS, Textor SC, Grill DE, et al. Incidence and prognostic importance of acute renal failure after percutaneous coronary intervention. Circulation 2002;105:2259-64. http://dx.doi.org/10.1161/01.CIR. 0000016043.87291.33

22. Lasser EC, Lyon SG, Berry CC. Reports on contrast media reactions: analy- 
sis of data from reports to the U.S. Food and Drug Administration. Radiology 1997;203:605-610.

http://dx.doi.org/10.1148/radiology.203.3.9169676

23. Nikolsky E, Mehran R, Turcot D, et al. Impact of chronic kidney disease on prognosis of patients with diabetes mellitus treated with percutaneous coronary intervention. Am J Cardiol 2004;94:300-05. http://dx.doi.org/10.1016/j.amjcard.2004.04.023

24. Kwasa EA, Vinayak S, Armstrong R. The role of inflammation in contrastinduced nephropathy. Br J Radio/ 2014;87:20130738. http://dx.doi.org/10.1259/bjr.20130738

25. Kaya A, Kurt M, Tanboga IH. Neutrophil-to-lymphocyte ratio predicts contrast-induced nephropathy in patients undergoing primary percutaneous coronary intervention. Angiology 2014;65:59. http://dx.doi.org/10.1177/0003319713502847

26. Mansi IA. In vitro effects of coronary angiography: Unknown clinical implications. Med Hypotheses 2009;73:389-92. http://dx.doi.org/10.1016/.mehy.2009.02.035

27. Feldman LJ, Chollet-Martin S, Himbert D, et al. Modulation of the expression of the granulocyte adhesion molecule, CR3, by percutaneous transluminal coronary angioplasty and contrast media. Invest Radiol
1994;29:313-18. http://dx.doi.org/10.1097/00004424-199403000-00011 28. Antunez C, Barbaud A, Gomez E, et al. Recognition of iodixanol by dendritic cells increases the cellular response in delayed allergic reactions to contrast media. Clin Exp Allergy 2011;41:657-64. http://dx.doi.org/10.1111/j.1365-2222.2010.03693.x

29. Gomez E, Ariza A, Blanca-Lopez N, et al. Nonimmediate hypersensitivity reactions to iodinated contrast media. Curr Opin Allergy Clin Immunol 2013;13:345-353. http://dx.doi.org/10.1097/ACl.0b013e328362b926

30. McClellan W, Aronoff SL, Bolton WK, et al. The prevalence of anemia in patients with chronic kidney disease. Curr Med Res Opin 2004;20:150110. http://dx.doi.org/10.1185/030079904X2763

31. Morabito S, Pistolesi V, Benedetti G, et al. Incidence of contrast-induced acute kidney injury associated with diagnostic or interventional coronary angiography. J Nephrol 2012;25:1098-107. http://dx.doi.org/10.5301/jn.5000101

32. Idee JM, Beaufils $H$, Bonnemain B. lodinated contrast media-induced nephropathy: pathophysiology, clinical aspects and prevention. Fundamental \& Clinical Pharmacology 1994;8:193-206. http://dx.doi.org/10.1111/j.1472-8206.1994.tb00799.x

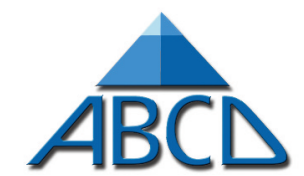

Association of British Clinical Diabetologists

\section{Insulin degludec (Tresiba) Nationwide Audit in progress}

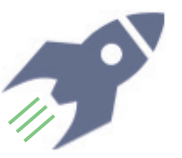

$A B C D$ has launched a nationwide audit of insulin degludec in the UK to assess real clinical efficacy and safety \& inform future practice and guidelines Does your centre use insulin degludec?

If yes, REGISTER YOUR CENTRE! by contacting degludec.audit@diabetologists.org.uk

- you are invited to enter your patients' data into the bespoke online tool

- you are able to analyse your local data easily

- the data will be automatically added to the national data in anonymised form

- we can provide easy-to-complete paper proformas for use in clinic if preferred

Please remember: - the more data, the more complete our understanding of insulin degludec in real clinical practice will be

- all contributors will be listed in publications arising from data submission 